PALEO

Revue d'archéologie préhistorique

$14 \mid 2002$

Varia

\title{
Gabriel Camps (1927- 2002)
}

\section{F. Bazile}

\section{OpenEdition}

Journals

Édition électronique

URL : http://journals.openedition.org/paleo/1380

DOI : $10.4000 /$ paleo.1380

ISSN : 2101-0420

Éditeur

SAMRA

Édition imprimée

Date de publication : 1 décembre 2002

Pagination : $9-10$

ISSN : 1145-3370

\section{Référence électronique}

F. Bazile, « Gabriel Camps (1927- 2002) », PALEO [En ligne], 14 | 2002, mis en ligne le 09 août 2010, consulté le 22 juillet 2020. URL : http://journals.openedition.org/paleo/1380 ; DOI : https://doi.org/ 10.4000/paleo.1380

Ce document a été généré automatiquement le 22 juillet 2020.

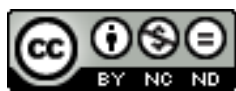

PALEO est mis à disposition selon les termes de la licence Creative Commons Attribution - Pas d'Utilisation Commerciale - Pas de Modification 4.0 International. 


\section{Gabriel Camps (1927- 2002)}

\section{F. Bazile}

1 Gabriel Camps est décédé à Aix-enProvence, le 6 septembre 2002. Il nous laisse une œuvre considérable consacrée essentiellement à la Préhistoire et à la Protohistoire de la Méditerranée occidentale, plus particulièrement $d u$ Maghreb, mais également de la Corse, son dernier "terrain".

2 Né le 20 mai 1927 à Misserghin, en Oranie, il fit toutes ses études en Algérie, au Lycée d'Oran puis à la faculté de lettres d'Alger, études couronnées par le doctorat ès lettres.

3 Ses deux thèses, toutes les deux titrées Aux origines de la Berbérie, préfigurent

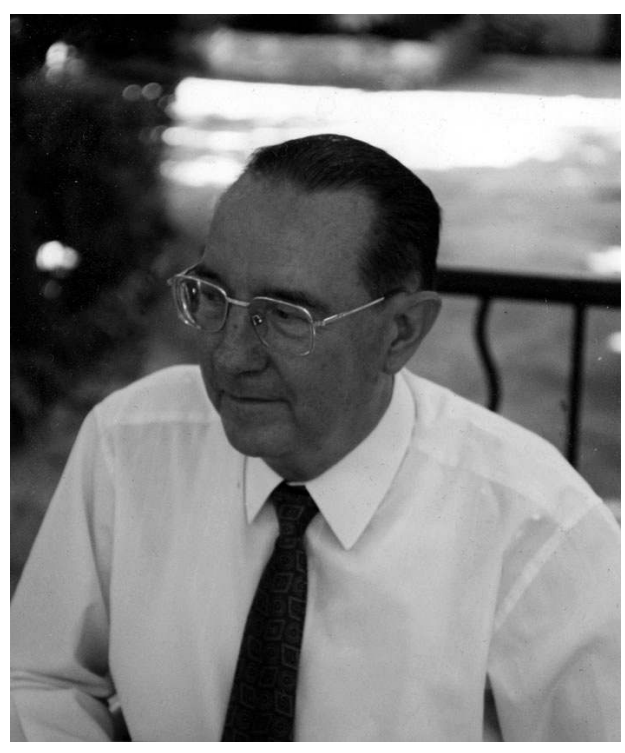
l'orientation de ses travaux futurs. L'une, sous-titrée Massinissa ou les débuts de l'histoire (1960), consacrée au grand roi numide, abordait les premiers temps de l'histoire de l'Afrique du Nord, l'autre, sa thèse principale, sous-titrée Monuments et rites funéraires protohistoriques (1961) affirmait sa prédilection pour la Préhistoire récente et la Protohistoire.

Il commença sa carrière dans le secondaire avant d'entrer au C.N.R.S en 1959. Il collabora alors étroitement au Centre de Recherches Anthropologiques, Préhistoriques et Ethnographiques (C.R.A.P.E.), fondé et dirigé alors par L. Balout.

5 En 1962, à la fin de la guerre d'Algérie, il succéda comme directeur du C.R.A.P.E. à L. Balout, dirigeant en même temps le Musée du Bardo et la revue Libyca ; il est également nommé Professeur à la faculté des lettres d'Alger.

6 En 1968, il quitte l'Algérie et rejoint Aix-en-Provence, nommé (1969) comme professeur à l'Université de Provence. Il créait le Laboratoire d'Anthropologie et de Préhistoire de 
la Méditerranée Occidentale (LAPEMO puis L.A.P.M.O., devenu aujourd'hui l'E.S.E.P.), reprenant en partie les thématiques du C.R.A.P.E. algérien mais en élargissant le champ des problématiques. En témoignent les directions d'ouvrages collectifs de cette période comme le colloque L'Homme de Cro-Magnon (1970) ou la table ronde l'Epipaléolithique méditerranéen (1975).

Gabriel Camps accueille au L.A.P.M.O. de nombreux étudiants venus notamment du Maghreb mais également d'Afrique Noire. Le L.A.P.M.O. devient dans les années 1980 le grand centre de la Préhistoire en France méditerranéenne avec la soutenance de nombreuses thèses pour la plupart dirigées par G. Camps ; beaucoup, dont nous-même, gardent en mémoire la valeur et la rigueur de son enseignement et surtout les qualités humaines avec lesquelles il le dispensait. Les séminaires de troisième cycle sont longtemps restés le "forum" de la Préhistoire de la France Méditerranéenne ; la quasitotalité des Préhistoriens provençaux et languedociens y participent.

Son épouse, Henriette Camps-Fabrer, resta toujours étroitement associée à l'enseignement comme elle le fut sur le terrain en Algérie ou dans l'étude du mobilier archéologique. Elle joua un rôle essentiel dans la réussite du L.A.P.M.O., auprès des étudiants surtout ; nombreux sont ceux qui ne l'ont pas oubliée.

Les Camps avait acquis au retour d'Algérie une maison aux Eyzies; très attachés au Périgord, ils y passaient leurs vacances...

$\mathrm{Au}$ cours de quarante ans de carrière, Gabriel Camps aborda de nombreux thèmes de recherches, y compris l'ethnographie, avec cependant une préférence marquée pour la période préromaine en Afrique du Nord: on peut énumérer sans être exhaustif, les royaumes berbères, le monde punique, l'épigraphie libyque et les tribus d'Afrique, sans oublier les croyances et même Rome. Il aborda peu le Paléolithique et l'Epipaléolithique préférant le Néolithique et les Ages des Métaux; il s'intéressa tout spécialement aux monuments funéraires pré-islamiques dont il établit une classification, déterminant de nouveaux types encore en usage. Il s'intéressa également à la céramique modelée et peinte liée aux dolmens et aux tumulus; il reconnut la présence de la céramique campaniforme au Maghreb et démontra l'existence d'un âge du bronze en Afrique du Nord, existence jusque là niée par les historiens et les archéologues.

11 Son activité déborda largement le cadre de l'Algérie proprement dite, le Sahara - dans le cadre de l'Institut de Recherches Sahariennes de l'Université d'Alger, avec en particulier l'examen des gravures et peintures rupestres lors de nombreuses missions au Hoggar et au Tassili - mais également le Maroc et la Tunisie ; il participa activement à l'Atlas préhistorique de ce dernier pays.

12 Le monde berbère resta constamment au cœur de ses préoccupations; il publiera sur ce sujet deux livres et de nombreux articles; il fonda, il y a trente ans, et dirigea depuis l'Encyclopédie berbère, rédigeant un très grand nombre de notices (vingt-quatre volumes parus, soit plus de 4000 pages pour moitié de sa main). Jusqu'à la fin de sa vie il poursuivra cette entreprise, restée inachevée.

13 Sa curiosité le porta enfin vers la navigation en Méditerranée, le peuplement des îles et en particulier la circulation de l'obsidienne, un des phénomènes marquants du Néolithique moyen méditerranéen; cela le conduisit tout naturellement à s'intéresser à la Corse, son dernier terrain, à laquelle il consacra plusieurs articles et un livre important paru en 1988. 
Il faudrait rappeler aussi sa participation active à de nombreux congrès et colloques et son rôle dans la gestion et l'administration de la recherche. Il siégea au Conseil permanent de l'Union internationale des sciences préhistoriques et protohistoriques, au Comité National du C.N.R.S. (section 33) et au Comité des travaux historiques et scientifiques; il géra le LAPMO durant de nombreuses années. Il participa à un grand nombre de jurys de thèses, dirigeant de nombreux travaux de la Maîtrise au Doctorat d'état.

La liste des travaux de G. Camps s'étend sur environ dix-huit pages dactylographiées et on pourra la consulter dans L'Homme Méditerranéen, Mélanges offerts par ses amis et ses élèves en 1995 ; une liste exhaustive

est en cours de finalisation à l'ESEP. Ses travaux lui valurent de nombreuses distinctions comme la qualité de membre de l'Académie des Sciences d'Outre Mer et celle de correspondant de l'Institut, Académie des Inscriptions et belles Lettres.

Parmi ce qui n'est qu'une toute petite partie de son œuvre nous citerons :

Les Civilisations Préhistoriques de l'Afrique du Nord (Doin Paris 1974), un Manuel de Recherche Préhistorique qui connu deux éditions (Doin, Paris 1979 et Doin, Paris 1990), Berbères aux marges de l'Histoire (Ed. Hespérides Toulouse 1980 et 2ème Ed. Errance, Paris, 1987), La Préhistoire: à la recherche du paradis perdu (Perrin, Paris 1982), Préhistoire d'une île : les origines de la Corse (Errance, Paris 1988) et, enfin, L'Afrique du Nord au féminin (Perrin, Paris, 1992).

Dans ce dernier ouvrage Gabriel Camps, bien au-delà du Préhistorien qu'il était, nous brosse les portraits d'une vingtaine d'héroïnes, de la "Capsienne" de l'Atlas, quelques 6000 ans avant notre ère, à cette grande dame kabyle emportée dans le tourbillon de la guerre d'indépendance...

Tous ceux qui n'ont pas connu Gabriel Camps découvriront dans ces textes d'un véritable auteur de talent, l'homme avant le savant, l'homme curieux et généreux, sensible et attachant, l'homme ouvert sur le monde, la vie, l'homme ouvert sur les autres. 